\section{O PATHOS NO CINEMA}

\section{Jéssica Cordeiro}

Graduanda em Filosofia

Universidade Federal da Bahia

\section{RESUMO}

Este ensaio tem como objetivo investigar o conceito de Pathos (ação patética) presente na Poética de Aristóteles e sua apropriação pelo cinema clássico dos anos 20, através do aprofundamento teórico de Sergei Eisenstein, no Cinema Soviético, e da análise da obra cinematográfica "A paixão de Joana d'Arc" (La passion de Jeanne d'Arc), clássico do cinema mudo europeu.

Palavras Chave: Pathos, Estética, Cinema.

\section{ABSTRACT}

This paper aims to investigate the concept of Pathos (pathetic action) present in Aristotle's Poetics and its adaptation to the classic cinema of the 1920s, through the theoretical deepening of Sergei Eisenstein in the Soviet Cinema and analysis of cinematographic work "The Passion of Joan d'Arc "(The Passion of Jeanne d'Arc), a classic of European silent films.

Key-words: Pathos, Esthetics, Cinema.

Aristóteles instaura com A Poética a primeira sistematização da arte, mais especificamente da mímese de ações humanas realizadas nas narrativas poéticas. Se, por um lado, busca investigar a natureza da arte poética, por outro, assume uma função prescritiva, de orientação da composição do poema, para fins de se obter êxito. "Falemos da arte poética, dela mesma, [...] do arranjo que devem ter os enredos se há de ser exitosa a produção poética" (GAZONI, 2006, p. 30). Estão ali ordenados os critérios que permitem julgar a boa execução da obra e que possibilitam, por exemplo, ao próprio Aristóteles classificar Sófocles como autor das mais belas tragédias ou Eurípedes como o mais trágico dos poetas. $\mathrm{O}$ homem, segundo Aristóteles, é potencialmente apto a realizar a mimese, já que a "representação" faz parte da natureza humana e de seu processo de aprendizado. E é através da premissa de que o ato de conhecer é prazeroso ao homem que Aristóteles explica o prazer obtido pela contemplação de mimesis mórbidas, terrificantes ou pungentes.

"[...] contemplamos com prazer, por exemplo, as figuras das feras sórdidas e dos cadáveres. A causa disso é que aprender é prazeroso não apenas para os filósofos, mas também, de modo semelhante, para os outros [...] por isso comprazem-se olhando as imagens, porque ocorre que, ao contemplá-las, aprendem e

\footnotetext{
${ }^{1}$ Não irei me deter à discussão de um termo que traduza o conceito de mimesis, visto a dificuldade da tarefa. Utilizo no texto o termo proposto por Dupont-Roc e Lallot, "representation".
} 
montam raciocínios do que é cada coisa" (GAZONI, 2006, p. 41).

O prazer estaria, então, relacionado à associação cognitiva do objeto representado ao seu correspondente no mundo real, à um objeto previamente conhecido. A mímese em si é poética $($ poien $=$ produzir $)$, produtora/criadora, $\mathrm{e}$ o faz a partir do material já dado pela própria natureza humana. Ao representar ações humanas, estas são mediadas pelo caráter virtuoso ou vicioso do homem, mimetizados na tragédia e na comédia, respectivamente.

Embora Aristóteles esboce uma ideia a respeito da comédia - e sugira no capítulo 6 voltar a falar sobre ela -, conclui A Poética sem realizar nenhum aprofundamento, dedicando quase toda sua obra ao desenvolvimento da teoria da tragédia.

O enredo, a "trama dos fatos", principal elemento da tragédia, é dividida em duas categorias: enredo simples e enredo complexo, sendo esta distinção própria da natureza mesma das ações mimetizadas (ações simples e ações complexas). Em ambos ocorrem o que Aristóteles denomina como metabasis (mudança de fortuna), momento em que o personagem percorrendo determinado curso depara-se com um desvio, levando-o da fortuna ao infortúnio. O que distingue o enredo complexo é a presença da peripeteia (peripécia, reviravolta) e/ou da anagnorisis (reconhecimento). A peripécia sendo também um elemento que configura uma mudança no curso da ação, mas uma mudança que é dada, especificamente, pelo seu contrário, e, o reconhecimento sendo o despertar de um estado de ignorância para o conhecimento, como Édipo ao reconhecer-se filho de Laio e Jocasta. A mais bela tragédia, para Aristóteles, deve ser complexa e realizar a mímese de ações que provoquem sentimentos de temor e piedade. A importância dada à presença do temor e da piedade, sugere que, além das funções descritivas e prescritivas a que $\mathrm{A}$ Poética se atribui, existe a busca por um fim ou um efeito provocado pela arte, como a catarse (kátharsis, "purificação"). A tragédia, portanto, para além do mero entretenimento, tem como finalidade realizar a purgação das paixões.

O pathos (evento patético) encontra-se na estrutura do efeito catártico. Aristóteles descreve o evento patético como "uma ação destrutiva ou dolorosa, como as mortes, os sofrimentos e ferimentos em cena e tudo quanto seja desse tipo" (GAZONI, 2006, p. 79). Atribui-se mais valor à obra onde esses elementos constituem a natureza do desdobrar da ação, limitá-los aos recursos materiais não constitui a essência própria da tragédia. Por isso, para Aristóteles o espetáculo é o elemento menos importante 
e mais estranho à poesia. $\mathrm{O}$ temível e o piedoso dever nascer "do próprio arranjo das ações" (GAZONI, 2006, p. 86) conectado por uma estrutura coesa determinada pelo necessário e pelo verossímil.

A verossimilhança, possibilidade, no que tange à vida humana, é a estrutura lógica do enredo. Ela dita as expectativas humanas dentro da ação, já que o futuro é inevitavelmente imprevisto, fortuito, circunstancial. Por outro lado, o arranjo das ações sucede sempre um passado necessário.

Segundo o Dicionário de Filosofia (ABBAGNANO, 1998, p. 745), o termo "patético" está relacionado ao conceito de "sublime", já reflexo do romantismo alemão, do século XVIII. Ele aparece como uma das espécies do sublime, designada por Friedrich Schiller.

"Em sentido próprio e estrito, o Sublime é o prazer que provém da imitação (ou contemplação) de uma situação dolorosa. Com esse sentido, essa noção vem diretamente do conceito aristotélico de tragédia - que deve provocar "piedade e temor"; por isso, como diz Aristóteles, o poeta trágico "deve propiciar o prazer que nasce da piedade e do terror por meio da imitação"”, (ABBAGNANO, 1998, p. 923).

O sublime está fundamentado na dor, referindo-se a expressões, ações e atitudes de valores nobres ou elevados. Nesse sentido, percebe-se as aproximações do pathos (e do sublime) à moralidade. Para Benedetto Croce (1912, apud ABBAGNANO, 1998, p. 923), o sublime é uma "afirmação subitânea de uma força moral poderosíssima".

\section{O patético em Eisenstein}

Sergei Eisenstein, um dos mais importantes cineastas soviéticos e teórico do cinema, forneceu grandes contribuições em um esforço de sistematização e teorização da linguagem cinematográfica, expressão artística concebida a partir da invenção do cinematógrafo pelos irmãos Lumière, em 1895.

Eisenstein (2002a, p. 149) concebe o filme em uma estrutura de duas dimensões: o orgânico e o patético. O orgânico na composição cinematográfica se refere às leis internas que gerem o filme em sua totalidade, e cada uma de suas partes em particular, formando uma estrutura viva e coesa. Uma segunda qualidade orgânica diz do fato da construção da representação pictórica corresponder às leis dos fenômenos naturais, isto é, quando a obra espelha os fenômenos do mundo real. Poderíamos supor que, nesse sentido, o orgânico na composição da obra cinematográfica, diz 
respeito à qualidade mimética de sua construção?

A dimensão patética de uma obra é dada, sobretudo, pelo exame de sua percepção pelo fruidor e pelos efeitos, inclusive fisiológicos, que lhe causa. "O filme é concebido como um organismo que artificialmente reproduz o orgânico da natureza. Por isso emociona os humanos que também são parte da natureza" (GONÇALVES, 2010). A ação patética em Eisenstein é responsável por conduzir o espectador a um estado de êxtase. Compreende-se aqui o sentido grego da palavra Ékstasis, "sair fora de si". "Sair do estado habitual", "Condição daquele que está emocionalmente fora de si ou tomado por sensações adversas, intensas e contundentes", circunstância em que aquele estando sentado levantou, estando imóvel moveu-se, estando calado gritou. É importante ressaltar que sair de si mesmo, no conceito da obra patética, não corresponde a "sair para o nada", mas, necessariamente, passar de uma condição para a sua contrária. Cabe dizer também que, estando Eisenstein inserido na tradição do Cinema Soviético, a emoção suscitada pela obra deve sempre ser uma emoção engajada, marcada por uma tomada de consciência social.

"Nestes pontos de passagem para o contrário acontece o patético. Eisenstein define-o pelos efeitos no espectador. Este é tomado por um estado de êxtase, por uma vontade de "saltar na cadeira". Não se trata contudo da emoção pela emoção mas de uma tomada de consciência e de uma elevação moral. O espectador compreende que chegou o momento de ser requisitado a tomar parte na história e cumprir seu papel contra a injustiça social" (GONÇALVES, 2010).

Da passagem do conceito de ação patética na Antiguidade Clássica para a sua apropriação pelo meio cinematográfico no século XX, compete analisar de que modo a especificidade técnica e a linguagem própria do cinema opera o pathos dentro da narrativa. Essa preocupação é explicitada na teoria de Eisenstein:

"[...] com que métodos e meios deve o fato retratado filmicamente ser tratado a fim de que mostre, simultaneamente, não apenas $o$ que é o fato, e a atitude do personagem em relação ao fato, mas também como o autor se relaciona com o fato, e como o autor quer que o espectador receba, sinta e reaja ao fato retratado" (EISENSTEIN, 2002a , p. 142).

Breve análise do pathos em "A paixão de Joana d'Arc"

Entre os planos de construção cinematográfica, o close, aquele que apresenta em uma visão micro um objeto, um rosto ou outra parte do corpo, é um 
plano atípico, quase que genuinamente cinematográfico. Apresenta-se como um ângulo visual ao qual nossos olhos não estão acostumados, em raras situações vêse alguém tão de perto, por exemplo.

Em "A paixão de Joana d'Arc", filme de 1928, dirigido por Carl Theodor Dreyer, os enquadramentos são quase que completamente construído por planos em close. Essa aproximação excessiva têm por objetivo produzir sentido em relação à própria obra e por isso é tão importante em sua análise. $\mathrm{O}$ close funciona como um instrumento, uma espécie de raio-x da alma humana, de seu caráter, distinguindo pictoricamente o humano virtuoso do seu oposto.

A proximidade da câmera em relação ao objeto filmado, neste caso os rostos dos personagens, destaca e revela o interior de cada um, levando a uma densidade psicológica. Assim vemos em Maria Falconetti (Joana d'Arc) um misto de dor e compaixão, fragilidade e força, santidade e humanidade; enquanto nos rostos dos seus inquisidores são destacadas as rugas, verrugas, as imperfeições que exprimem suas personalidades ${ }^{2}$. A relação estabelecida entre Joana e seus inquisidores é ainda evidenciada pelos enquadramentos da personagem, quase sempre em plongée, em oposição aos

${ }^{2}$ Figura 01. enquadramentos do júri, quase sempre em contra-plongée, recurso que a deixa pequena, humilhada perante os personagens do clero, afirmando seu padecimento, sua passividade perante $\mathrm{o}$ sofrimento e, principalmente, sua humanidade contraposta à posição do clero $^{3}$. A composição da obra, portanto, potencializa a ação patética, já que, segundo Aristóteles (2002, p.83), “a piedade se dá em relação ao que não merece, o temor em relação ao semelhante".

A experiência estética que a obra nos propicia é permeada pela estrutura patética, pela inspiração dos sentimentos que provoca no espectador. Ao ver o destino ao qual se aproxima a personagem, e o temor, a angústia, o sofrimento em seus olhos, somos impelidos a experienciar esses sentimentos e, em certo sentido, padecemos junto com ela. "[...] tanto as estruturas pictóricas quanto as de composição são fundidas na unidade soldada de uma imagem aterrorizante" (EISENSTEIN, 2002 ${ }^{\mathrm{a}}, \quad$ p. 143). A composição tensiona os elementos da ação patética. Somos submetidos ao êxtase, forçados a abandonar nossa condição habitual.

A estrutura patética em "A paixão de Joana d'Arc" está tão bem encadeada

\footnotetext{
${ }^{3}$ Figura 02 .
} 
que, metalinguisticamente, a personagem do filme "Viver a Vida" ("Vivre as vie", de 1962), de Jean-Luc Godard, vai ao cinema e, assistindo A paixão de Joana d'Arc, vivencia o efeito da ação patética ${ }^{4}$.

A Poética de Aristóteles permanece sendo um importante referencial para a arte, sobretudo para as linguagens que trabalham as narrativas. Considerando todo o percurso da arte ao longo da história: o movimento literário do romantismo alemão, a primeira vez que um artista levou seu cavalete para rua, a invenção do cinematógrafo pelos irmãos Lumière, o ready made, a performance e o happening, John Cage "tocando o silêncio", Malevich compondo "um quadrado negro sobre um fundo branco"; haveria ainda espaço para a rigidez das normas, da composição precisa? Qual seria o lugar da Poética para além da Antiguidade Clássica? É fato que A Poética permanece sendo lida e revisitada por diferentes linguagens, como a literatura, as artes cênicas e o cinema. E que, além das funções descritivas e prescritivas a que ela se propõe, existe a busca por um fim provocado pela arte. Sobrevivendo às críticas que afirmavam que a formulação de leis externas que incidem sobre a composição artística limita o processo de criação, seus conceitos (mudança de fortuna, peripécia,

${ }^{4}$ Figura 03. reconhecimento, evento patético, falha trágica, etc.) foram apropriados pelos esquemas de roteirização para cinema, por exemplo, e são facilmente identificáveis na maior parte da produção cinematográfica. Não faltam exemplos que afirmem a utilidade dos conceitos defendidos na teoria da tragédia e de que mesmo para subverter a "tradição" é preciso em certo sentido conhece-la.

\section{Referências Bibliográficas}

ABBAGNANO, Nicola. Dicionário de Filosofia. Tradução: Alfredo Bosi. 2 ed. São Paulo: Martins Fontes, 1998.

EISENSTEIN, Sergei. A Forma do Filme. Tradução: Teresa Ottoni. Rio de Janeiro: Jorge Zahar Ed., 2002a.

EISENSTEIN, Sergei. O Sentido do Filme. Tradução: Teresa Ottoni. Rio de Janeiro: Jorge Zahar Ed., 2002b.

GAZONI, Fernando Maciel. A Poética de Aristóteles: Tradução e Comentários. São Paulo: USP, 2006. 131 p. Tese (Mestrado) - Programa de PósGraduação em Filosofia, Departamento de Filosofia da Faculdade de Filosofia, Letras e Ciências Humanas, Universidade de São Paulo, São Paulo, 2006.

GONÇALVES, Jorge. Sergei Eisenstein. [On-line]. 2010. 
Disponibilidade:

http://filmphilosophy.squarespace.com/1sergei-eisenstein. [05/05/2017].

Anexos

Figura 01 - O caráter exprimido em termos pictóricos

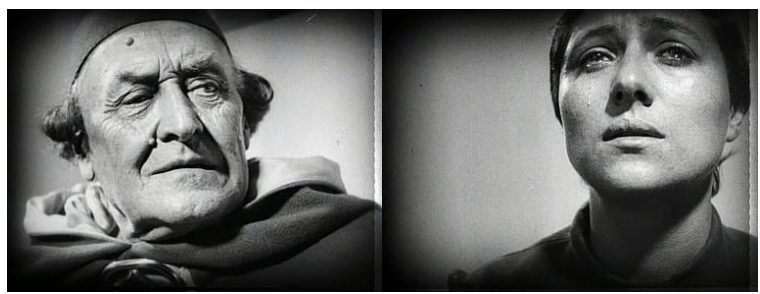

Figura 2 - Os enquadramentos em contraplongée e plongée, evidenciando a sujeição da personagem

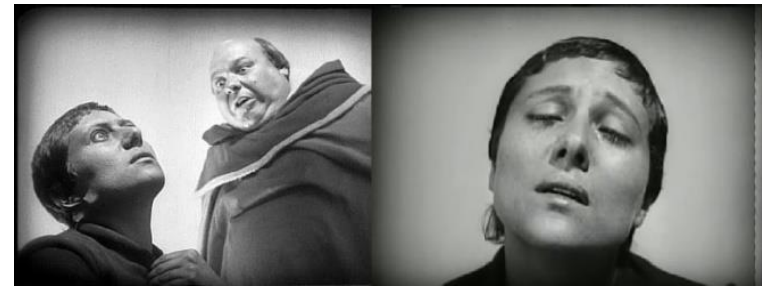

Figura 3 - Nana, personagem de Viver a Vida, assiste A paixão de Joana d'Arc

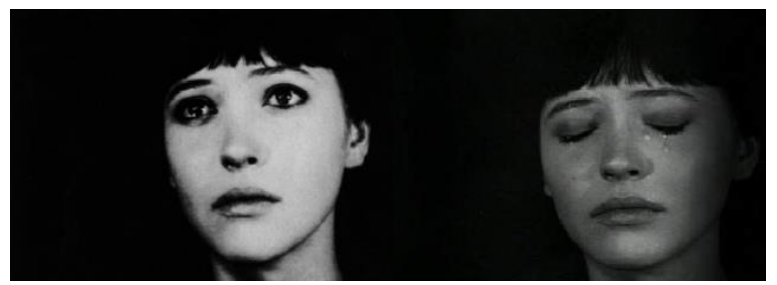

